\title{
Quantifying uncertainty in predictions of invasiveness, with emphasis on weed risk assessment
}

\author{
Peter Caley $\cdot$ W. M. Lonsdale · P. C. Pheloung
}

Published online: 16 March 2007

(C) Springer Science+Business Media B.V. 2007

\section{Erratum to: Biol Invasions DOI 10.1007/s10530-004-0010-6}

Due to a technical error, the following article has been accepted and published twice. "Quantifying uncertainty in predictions of invasiveness in predictions of invasiveness, with emphasis on weed risk assesment" by P. Caley, W. M. Lonsdale \& P.C. Pheloung, published in Volume 8, Issue 2 (pages 277-286) of the Biological Invasions Journal was accidentally published again in Volume 8, Issue 8 (pages 1595-1604).

The online version of the original article can be found at http://dx.doi.org/10.1007/s10530-004-0010-6

P. Caley - W. M. Lonsdale

CSIRO Entomology, GPO Box 1700, Canberra, ACT

2601, Australia

P. Caley $(\bowtie) \cdot$ W. M. Lonsdale · P. C. Pheloung Cooperative Research Centre for Australia Weed Management, PMB 1, Waite Campus, Glen Osmond, SA 5064, Australia

e-mail: Peter.Caley@csiro.au

P. C. Pheloung

Department of Agriculture, Fisheries and Forestry, GPO Box 858, Canberra, ACT 2601, Australia 